\title{
Elementos Teóricos e Sociais da Paisagem em Áreas Urbanas: um estudo semiótico no caso de Itapuranga - GO
}

\author{
Theoretical and Social Elements of the Landscape in Urban Areas: a semiotic study \\ in the case of Itapuranga - GO
}

\author{
Elementos Teóricos y Sociales del Paisaje en Áreas Urbanas: un estudio semiótico \\ en el caso de Itapuranga - GO
}

José Elias Pinheiro Neto ${ }^{1}$

Carlos Eduardo de Oliveira Marins ${ }^{2}$

\begin{abstract}
RESUMO: O objetivo deste artigo é evidenciar as particularidades de uma comunidade por meio de uma hipótese científica utilizando a leitura das paisagens baseada na semiótica, uma vez que esta carrega uma série de elementos simbólicos que demonstram características intrínsecas que são produtos das relações que se desenrolam no meio social. Tais questões são debatidas mediante uma revisão bibliográfica que envolve a temática e observações empíricas na pesquisa de campo, além da coleta e análises de imagens fotográficas. Os resultados mostram que, a partir da leitura dos códigos e símbolos expressos no cenário social, trouxemos à tona algumas presunções que foram construídas ao longo das discussões teóricas, desvelando diversas relações sociais, políticas, econômicas e culturais contidas no espaço urbano de Itapuranga. Portanto, este trabalho evidencia a relevância da leitura das paisagens urbanas utilizando um viés alternativo no sentido de contextualizar e problematizar as diversas relações sociais entre os diferentes grupos dentro do espaço urbano.
\end{abstract}

PALAVRAS-CHAVE: Paisagem. Linguagem. Cidade.

ABSTRACT: The purpose of this article is to highlight the particularities of a community through a scientific hypothesis using the landscape reading based on semiotics, since it carries a series of symbolic elements that demonstrate the intrinsic characteristics are products of the relations that are social environment. These issues are debated through a literature review that involves thematic and empirical observations in field research, as well as the collection and analysis of photographic images. The results show that, from the reading of the codes and symbols expressed in the social scene, we brought up some assumptions that were constructed during the theoretical discussions, revealing

\footnotetext{
${ }^{1}$ Graduação em Letras pela Universidade Estadual de Goiás. Doutor em Geografia Humana pela Universidade de São Paulo (FFLCH/USP), Professor no Programa de Pós-Graduação Strictu Sensu em Língua, Literatura e Interculturalidade (POSLLI). Endereço: Avenida Rio Araguaia Esq. C/ Rio Paranaíba S/ №; Bairro: Setor Miltom Camilo de Faria, CEP 76680-000, Itapuranga - Goiás. joseeliaspinheiro@gmail.com.

2 Graduado em Geografia pela Universidade Estadual de Goiás, Campus Itapuranga. Especialista em Linguagem, Tecnologia e Ensino pela Universidade Estadual de Goiás, Campus Itapuranga. Endereço: Avenida Rio Araguaia Esq. C/ Rio Paranaíba S/ №; Bairro: Setor Miltom Camilo de Faria, Cep 76680-000, Itapuranga Goiás. carlosedumarins@gmail.com.
} 
diverse social, political, economic and cultural relations contained in the urban space of Itapuranga. Therefore, this work highlights the relevance of the reading of urban landscapes using an alternative bias in the sense of contextualizing and problematizing the diverse social relations between the different groups within the urban space.

KEYWORDS: Landscape. Language. City.

RESUMEN: El objetivo de este artículo es evidenciar las particularidades de una comunidad por medio de una hipótesis científica utilizando la lectura de los paisajes basada en la semiótica, una vez que ésta, lleva una serie de elementos simbólicos que demuestran características intrínsecas que son productos de las relaciones que se desarrollan en el medio social. Tales cuestiones, son debatidas mediante una revisión bibliográfica que envuelve la temática y observaciones empíricas en la investigación campo, además de la recolección y análisis de imágenes fotográficas. Los resultados muestran que, a partir de la lectura de los códigos y símbolos expresados en el escenario social, sacamos a la luz algunas presunciones que se construyeron a lo largo de las discusiones teóricas, desvelando diversas relaciones sociales, políticas, económicas y culturales contenidas en el espacio urbano de Itapuranga. Por lo tanto, este trabajo evidencia la relevancia de la lectura de los paisajes urbanos utilizando un sesgo alternativo en el sentido de contextualizar y problematizar las diversas relaciones sociales entre los diferentes grupos dentro del espacio urbano.

PALABRAS-CLAVE: Paisaje. Idioma. Ciudad.

\section{INTRODUÇÃO}

Localizada na microrregião de Ceres, Itapuranga é mais um entre centenas de pequenos municípios do estado de Goiás. Situado no centro goiano, o município conta com uma população total de 26.586 pessoas, segundo a estimativa dada pelo Instituto Brasileiro de Geografia e Estatística em seu último censo (IBGE, 2017). O município conta com uma área territorial de 1.276,479 quilômetros quadrados. São limítrofes à Itapuranga os municípios de Carmo do Rio Verde, Faina, Goiás, Guaraíta, Heitoraí, Morro Agudo de Goiás, São Patrício e Uruana.

De início, trazemos a análise a partir de uma "pequena cidade" para esclarecer que, apesar de estarmos pesquisando uma cidade de pequeno porte, a produção do espaço urbano de Itapuranga obedece à mesma lógica dos grandes centros ou de qualquer outra cidade, pois a análise dos elementos teóricos e sociais da paisagem proposta neste trabalho não se limita a determinados parâmetros e/ou modelos urbanos.

Vivemos em um mundo metamórfico onde todos os elementos a nossa volta se modificam a todo instante, o ser humano tem a capacidade de construir e destruir as coisas e ao mesmo tempo em que isso acontece ocorre modificações nas paisagens. As marcas, as cores, os sons e as formas são pistas para entendermos o processo que ocorre no meio social, organizado e executado a mando dos sistemas. Com o passar dos anos, surgem 
novas rupturas nos processos de produção, nos métodos governamentais, enfim, nos diversos processos sociais que são idealizados principalmente por aqueles que estão no poder. Passamos por diversas mudanças de cunho político e econômico, assim o cenário social é reconfigurado, e os atores desta realidade são a sociedade como um todo. Por isso temos a ideia de que a paisagem foi (re)construída pela sociedade que antecede a esta e que hoje fazemos parte desta (re)produção social a mando do sistema capitalista de produção, ao mesmo tempo sendo amparados por leis que visam à ordem e o bem estar social. Trata-se de uma transformação do meio social, abordado aqui sob um olhar voltado para a cidade, na qual se evidenciam mudanças ocasionadas pelas relações entre os seres humanos e o meio ambiente ao longo dos anos.

A partir das diversas relações sociais elencadas no meio urbano, por meio de trabalhos coletivos e individuais, intermediados pelo meio político, as cidades ganham, cada vez mais, novas formas, novas "caras" em termos visuais e, às vezes, até estéticos. Criamse, com isso, ambientes distintos ao longo dos diversos pontos da área urbana. Neste sentido, a paisagem muda constantemente, cria-se um significado, e aos olhares mais atentos se torna uma comunicação visual. Diante disso, as paisagens vão se caracterizando de acordo com o relacionamento entre as pessoas dentro do ambiente social, e tais relacionamentos estão pautados principalmente no contexto político, econômico e cultural.

No âmbito social, o estudo da paisagem pode servir como um importante caminho para chegarmos a diversas conclusões acerca das realidades sociais, culturais e econômicas que estão presentes no meio dos diferentes grupos, independentemente de suas classes. As atividades desenvolvidas no meio social estão interligadas com a cultura, e esta com a natureza, entendida neste trabalho como o ambiente em que vive o homem e onde se desenrolam os fatos. No contexto da cidade podemos citar como exemplo a cultura dos pequenos e grandes comerciantes, do consumidor, dos moradores de rua, dos artistas de rua, dos religiosos, dos moradores do centro e da periferia, dos frequentadores de bares e casas noturnas, do vendedor ambulante e até a cultura dos excluídos, quer se trate dos usuários de drogas, dos traficantes ou dos pichadores, entre outros. Todos estes agentes se relacionam com o meio em que vivem, modificando-o e caracterizando este ambiente social, quer de forma direta ou indireta.

Partimos do princípio de que é consideravelmente relevante para o leitor/pesquisador que busca e que tem o interesse em se aprofundar no conhecimento que envolve as verdadeiras situações socioeconômicas de um determinado grupo social empregar o "poder" de interpretação da paisagem urbana, entendida aqui como aquela que foi construída e modificada por meio das relações sociais e que deixam registradas as marcas simbólicas que servem de aporte para um estudo voltado para a análise ambiental, visto que este tipo de estudo abrange uma gama de informações que estão enraizadas no cenário social. 
Elementos Teóricos e Sociais da Paisagem em Áreas Urbanas: um estudo semiótico no caso de...

A interpretação se realiza a partir da utilização dos nossos sentidos ao observarmos cores, volumes e formas, identificando assim os diferentes símbolos registrados. Por fim, é necessário compreendermos que o meio social está carregado de informações que (trans)formam os elementos da paisagem, e que, a partir da análise crítica e reflexiva, criam hipóteses no sentido de produzir possibilidades consideradas válidas antes mesmo de sua confirmação.

\section{A LINGUAGEM DA PAISAGEM EM ALGUMAS RELAÇÕES SOCIAIS}

A paisagem é muito daquilo que nossos olhos alcançam, mas é válido dizer que ela está além disso. Para Souza (2013, p. 46, grifo do autor) "A paisagem é uma forma, uma aparência. O conteúdo 'por trás' da paisagem pode estar em consonância ou em contradição com essa forma e com o que ela, por hábito ou ideologia, nos 'sugere' [...]". Tal fato vai ao encontro do que o texto sugere: torna-se essencial o ato de indagar aquilo que se enxerga e o que se sente para que se chegue numa elucidação dos fatos e trazer à tona mais do que aquilo que se apresenta à primeira vista.

Temos um "leque" de elementos contidos na paisagem que nos dão um suporte primordial para trabalhar esta categoria, conforme pondera Santos (1994, p. 61), ao escrever que ela "Não é formada apenas de volumes, mas também de cores, movimentos, odores, sons etc". Portanto, podemos perceber que a paisagem não se limita apenas às aparências visuais, mas é de características muito mais abrangentes, fazendo com que ela se torne algo muito mais presente no cotidiano das pessoas. Partimos do princípio de que a paisagem da cidade é um conjunto destes elementos que se (re)configura a todo instante, isso acontece devido às relações que são produzidas entre as pessoas, ou seja, é o produto daquilo que acontece no meio social. As relações sociais desvelam muito das construções, da herança daqueles que transformaram a paisagem por interesses particulares ou coletivos.

\footnotetext{
A análise da paisagem é um método para se entender o mundo e as sociedades que, aliás, produzem, mantêm e compartilham as diversas paisagens e suas devidas valorações. Não há de maneira alguma uma distinção entre a paisagem que é supostamente real daquela que seria mera representação (NAME, 2010, p. 177).
}

A paisagem de uma cidade representa muito mais do que fisicamente ela apresenta, nela podemos vivenciar uma sociedade heterogênea em termos de cultura, educação e economia. Tais questões, na maioria das vezes, são percebidas por meio do que está em nossa volta. Maria (2010, p. 10) salienta que "[...] a paisagem expressa a cultura em seus diversos aspectos, revelando seu lado funcional e simbólico. Representa, assim, um 
elemento chave para a compreensão da realidade sociedade-cultura-natureza". A autora destaca, de modo geral, como a paisagem pode servir de leitura para compreendermos a realidade de uma sociedade em termos de relação entre três elementos: sociedade, cultura e natureza. A sociedade é encarada aqui como um conjunto de membros que vivem em grupos organizados e subordinados às mesmas leis ou preceitos, a cultura como um conjunto de conhecimentos adquiridos que se tornaram hábitos sociais e que caracteriza a sociedade e a natureza como o ambiente onde vive o homem e onde os fatos se desenrolam.

A sociedade urbana cria seus próprios hábitos de (sobre)vivência de acordo com as diversas possibilidades, por isso temos na cidade uma diversidade de atividades que são efetivadas no dia-a-dia, como exemplo podemos citar: o trabalho, os estudos, os encontros religiosos, os processos de compra e venda e as atividades de lazer, entre outras. Tais ações são exemplos de procedimentos que, de forma direta ou não, fazem com que o cenário social se reconfigure a todo instante e de forma instantânea. Neste sentido, cabe ao cidadão/pesquisador relacionar a "linguagem" da paisagem com a cultura, reconhecendo a importância de um conhecimento linguístico voltado para a compreensão dos símbolos para compreender certos hábitos e costumes de uma determinada comunidade, uma vez que:

[...] para compreender as expressões impressas por uma cultura em sua paisagem, necessitamos de um conhecimento da "linguagem" empregada: os símbolos e seu significado nessa cultura. Todas as paisagens são simbólicas [...] apesar de a ligação entre o símbolo e o que ele representa (seu referente) poder parecer muito tênue (COSGROVE, 2012, p. 227).

Para entendermos melhor a comunidade na qual estamos inseridos é fundamental que partamos da cultura, pois é ela que caracteriza uma sociedade ou um grupo de pessoas. Para Santos (2003, p. 22) a cultura "[...] diz respeito a tudo aquilo que caracteriza a existência social de um povo ou nação, ou então de grupos no interior de uma sociedade". Nesse sentido, podemos inserir as crenças, costumes, hábitos e culinária, entre outros, assim entendemos que cada cultura é expressa por meio de símbolos que estão impressos na paisagem.

De acordo com Cosgrove (1998, p. 32), a "[...] paisagem não se presta facilmente às restrições do método científico. Sua unidade e coerência estão, como vimos, enraizadas profundamente em uma maneira de ver, e isso permanece verdadeiro se a visão é a partir do solo, do ar ou do mapa". É por isso que este trabalho tem como desafio explicar teoricamente como os códigos, os sinais e as linguagens proferidos podem revelar as "verdades" encontradas nos diferentes territórios urbanos e confrontá-las com as realidades sociais e econômicas que se produzem no dia-a-dia destes locais. Trata-se de um estudo tendo como suporte a semiótica, esta que se define como sendo uma ciência que se dedica 
Elementos Teóricos e Sociais da Paisagem em Áreas Urbanas: um estudo semiótico no caso de...

aos estudos dos signos, que se torna fundamental nas análises dos detalhes encontrados nas paisagens, tendo como finalidade a busca e descrição da identidade formada a partir da realidade de determinados grupos sociais. Trata-se de um procedimento pouco usado na ciência geográfica visto que:

[...] nossa geografia deixa escapar muito do significado contido na paisagem humana, tendendo a reduzi-la a uma impressão impessoal de forças demográficas e econômicas. A ideia de aplicar à paisagem humana algumas das habilidades interpretativas que dispomos ao estudar um romance, um poema, um filme ou um quadro, de tratá-la como uma expressão humana intencional composta de muitas camadas de significados, é claramente estranha para nós. Entretanto, isso é o que me proponho a explorar, sugerindo maneiras de tratar a geografia como uma humanidade e uma ciência social (COSGROVE, 2012, p. 222).

A ideia deste autor nos mostra um viés alternativo, o qual a ciência geográfica deve seguir para estudar variados temas presentes nos diferentes contextos sociais. Podemos encontrar no estudo da semiótica uma abordagem dos elementos aqui elencados, trata-se de uma ciência que estuda as linguagens, além da oral e escrita, e estão incluídas, conforme Santaella (1983, p. 15), "[...] a linguagem das flores, dos ventos, dos ruídos, dos sinais de energia vital emitidos pelo corpo e, até mesmo, a linguagem do silêncio". O que se sugere, portanto, é realçar a relevância do uso de outros modos de linguagem, destacando a influência destes em temas transversais nos diferentes campos da ciência.

Cosgrove (2000, p. 39) escreve que as linguagens "[...] constituem a imaginação coletiva e definem a cultura não material. A linguagem é o modo primário da comunicação humana, constituidora da própria individualidade daqueles que a utilizam". Independentemente do local que nos encontramos, podemos estar cercados de códigos e sinais que estão inseridos no plano linguístico e que nos dão suporte necessário para fazermos uma leitura do nosso meio.

Cumpre notar que a ilusória exclusividade da língua, como forma de linguagem e meio de comunicação privilegiados é muito intensamente devida a um condicionamento histórico que nos levou à crença de que as únicas formas de conhecimento, de saber e de interpretação do mundo são aquelas veiculadas pela língua, na sua manifestação como linguagem verbal, oral ou escrita (SANTAELLA, 1983, p. 12).

$\mathrm{Na}$ área da linguística, temos a linguagem verbal como meio de comunicação, que pode ser representada pela fala e escrita. Porém nosso mundo está rodeado de elementos que são usados como forma de linguagem não verbal, trata-se de signos que são estudados e interpretados pela semiótica. É do campo desta ciência o estudo das linguagens verbais e não verbais, que colaboram para uma melhor compreensão de "mundo". 
Há, além dos signos da linguagem verbal, muitas outras espécies de signos que povoam de linguagens a vida do homem: a pintura, a mímica, o código de trânsito, a moda, as linguagens artificiais, etc. Os signos, em geral tanto das linguagens não-verbais quanto os da linguagem verbal, são objetos de uma ciência geral dos signos: a Semiologia (ORLANDI, 2003, p. 11).

As palavras da autora reforçam a ideia de que o mundo é formado por elementos que representam um determinado significado, e interpreta-los é um desafio ao qual o pesquisador está sujeito. Cada paisagem está carregada destes signos que fazem parte do dia-a-dia das pessoas, e por ventura são elas que os (re)produzem. A sociedade é a responsável pela (re)construção das paisagens. Neste sentido, entendemos que a linguagem abrange muito mais do que podemos ler e ouvir, ela pode ser desencadeada por meio da percepção, se tornando algo inclusivo.

\begin{abstract}
Sobrepondo a interpretação e a percepção, a linguagem pode ser compreendida inclusivamente, ao invés de exclusivamente. Palavras, imagens, objetos, usos e costumes, ao integrarem os processos de comunicação, podem ou não ocupar categorias separadas, mas contribuem para o entendimento do significado histórico e cultural que integra a mensagem (BACELAR, 1998, p. 7).
\end{abstract}

É importante destacar a visão do autor ao expor que as linguagens interpretadas por meio dos elementos não verbais, independentemente de ocuparem ou não categorias distintas, sempre contribuem para o entendimento dos significados desvelados nestes elementos, o que contribui para que os meios de comunicação entre a sociedade e a natureza se tornem mais abrangentes. Contudo, em se tratando de linguagem verbal ou não, é importante entendermos que os signos estão expressos em ambas, e que desvendálos é algo sempre possível.

Portanto, em nossas indagações, dúvidas e inquietações não podemos nos limitar em recorrer apenas aos meios impressos como os livros, revistas e jornais, às vezes as respostas estão à nossa volta, basta um olhar crítico e reflexivo acerca do que está visível para chegarmos às devidas conclusões. Muitas pessoas que direcionam seus estudos às leituras paisagísticas têm grandes chances de absorver melhor as realidades, mas, além disso, a curiosidade é sempre necessária.

A compreensão da paisagem nos leva para outra face daquela que enxergamos, neste processo podemos entender o contexto histórico da nossa formação como indivíduos sociais e principalmente as condições socioeconômicas na qual vivemos, além das crenças e simbolismos expressos no cenário social. Por meio da interpretação das paisagens urbanas percebemos a heterogeneidade, são cenários diversificados pautados em espaços de lazer, espaços de moradia, pontos comerciais e industriais, dentre outros. Essa heterogeneidade é uma característica não só da cidade, mas de um contexto conjuntural das paisagens, como 
aponta Santos (1994, p. 65), ao escrever que ela "[...] é um conjunto heterogêneo de formas naturais e artificiais; é formada por frações de ambas, seja quanto ao tamanho, volume, cor, utilidade, ou por qualquer outro critério. A paisagem é sempre heterogênea [...]".

Esta diversidade é uma qualidade daquilo que é natural e daquilo que foi modificado pelas mãos do homem, como é o caso da cidade que não só foi construída, mas é, também, modificada a todo instante a partir de (re)produções que são realizadas a partir dos interesses pessoais e coletivo. Para que se chegue ao objetivo proposto é preciso enxergar para além daquilo que nossos olhos alcançam, são os agentes sociais que (re)produzem as relações, falamos sobre a realização de uma leitura a partir do meio em que vivemos. É desta forma que:

[...] a paisagem se estrutura numa rede formada por uma miscelânea construída a partir de elementos naturais e artificiais, há uma junção concatenada de unidades desses elementos e dentro de uma sequência lógica se interconectam produzindo as paisagens a serem percebidas pelo observador. Dentro dessa lógica existem diversificadas variações para a formação desses elementos, consideramos as dimensões, as cores e o que mais estas variações podem nos oferecer para transformação de nossas atividades ou qualquer outro critério que sustente a heterogeneidade da paisagem (PINHEIRO NETO, 2017, p. 96).

A paisagem se torna um objeto de estudo das ciências naturais e humanas especialmente pela gama de informações que ela traz por meio de uma leitura detalhista, sistematizada por um estudo pautado em fundamentos reais. Sobre isso, Nunes (2002, p. 216) escreve que:

"[...] é como se estivéssemos em um teatro, diante de uma cenografia recém revelada por um abrir de cortinas. Bela ou feia, clara ou mal iluminada, próxima ou distante - não importa - somos atraídos pela paisagem como são os olhares dos espectadores atraídos pelo palco". Neste sentido, Maria (2016, p. 245) explica que:

[...] a paisagem não se reduz às informações visuais do mundo que nos cerca, pois será sempre especificada, de algum modo, pela subjetividade do observador, sendo esta subjetividade mais do que uma simples perspectiva ótica. Todavia, a paisagem se refere aos objetos concretos que existem à nossa volta e, ainda que o que ela representa ou evoca possa ser imaginário, ela sempre exigirá um suporte objetivo.

A partir da compreensão de paisagem exposta neste trabalho, cria-se uma ruptura em muitos conceitos do meio social que a projetam simplesmente como aquilo que se enxerga, ou ainda, muitos imaginam que seja o natural, o belo, o verde, a mata, os rios ou uma forma pictórica. O objetivo é findar a ideia que temos, para muitos, nas séries iniciais do Ensino Fundamental quando a professora de artes nos pede para desenhar uma paisagem e logo procuramos caprichar para desenhar as montanhas, o rio, os pássaros, a vegetação toda 
verde e um sol sorrindo. O fato é que o feio, o bonito, o sujo e o limpo faz parte dela, e o homem é parte da paisagem porque antes de se tornar um ser social, nasce biológico, é natural. É por meio dos nossos sentidos que classificamos um ambiente em seus diversos aspectos, ir mais fundo no estudo da paisagem é uma premissa de quem busca a verdadeira realidade acerca dos vínculos existentes no meio urbano entre os diversos indivíduos.

A partir do bojo teórico elencado, trazemos à tona a relevância de um olhar analítico sobre a cidade. Esta afirmação parte dos princípios da leitura de mundo, tendo como suporte a semiótica legitimada pelas teorias científicas que validam os elementos da paisagem, mostrando as diversas possibilidades de leitura pelos componentes que constituem a categoria.

\section{PAISAGEM URBANA: FATOS ANALISADOS NO CENTRO DE ITAPURANGA}

Diante do que foi exposto apresentaremos algumas imagens da área central e da periferia da cidade de Itapuranga, com o propósito de identificar componentes fundamentais que formam características singulares a determinadas realidades. A identificação que aqui propomos parte de uma exploração crítica de cada ambiente fotografado, no sentido de aguçar o leitor/pesquisador a se interessar pela análise dos pormenores e posicionar-se sempre de forma reflexiva.

A figura 1 é uma paisagem da área central de Itapuranga. Trata-se de um imenso conjunto de elementos característicos que constrói uma paisagem que se diferencia de outras por vários aspectos. O predominante destes aspectos é o fato de esta região se localizar no centro onde se situam as principais instituições públicas (prefeitura, câmara municipal, postos de saúde, hospitais etc.) onde também há um maior fluxo de pessoas e automóveis, além de ser o local mais visitado por turistas, visto que constituído por áreas de lazer, bares, restaurantes e comércio varejista.

Ao analisarmos determinadas particularidades podemos perceber algumas características que vão dando sentido à medida que se observa. $\mathrm{Na}$ imagem, temos a Praça Castelo Branco (consideravelmente extensa), fundada no ano de 1972. Leva o nome em homenagem ao primeiro presidente do período de regime militar. No interior da praça vemos um coreto onde são realizadas algumas apresentações artísticas em períodos festivos. Saindo desta praça temos a Avenida Anhanguera que liga o centro à igreja católica matriz, localizada no bairro São Sebastião do Xixá (também conhecido como "Xixazão"), local este que deu início à cidade. Este fato evidencia o poder exercido pela igreja católica que, mesmo depois de tornar-se afastada do centro, foram criados meios para facilitar o acesso da população central àquela instituição. 
Figura 1 - Praça central de Itapuranga

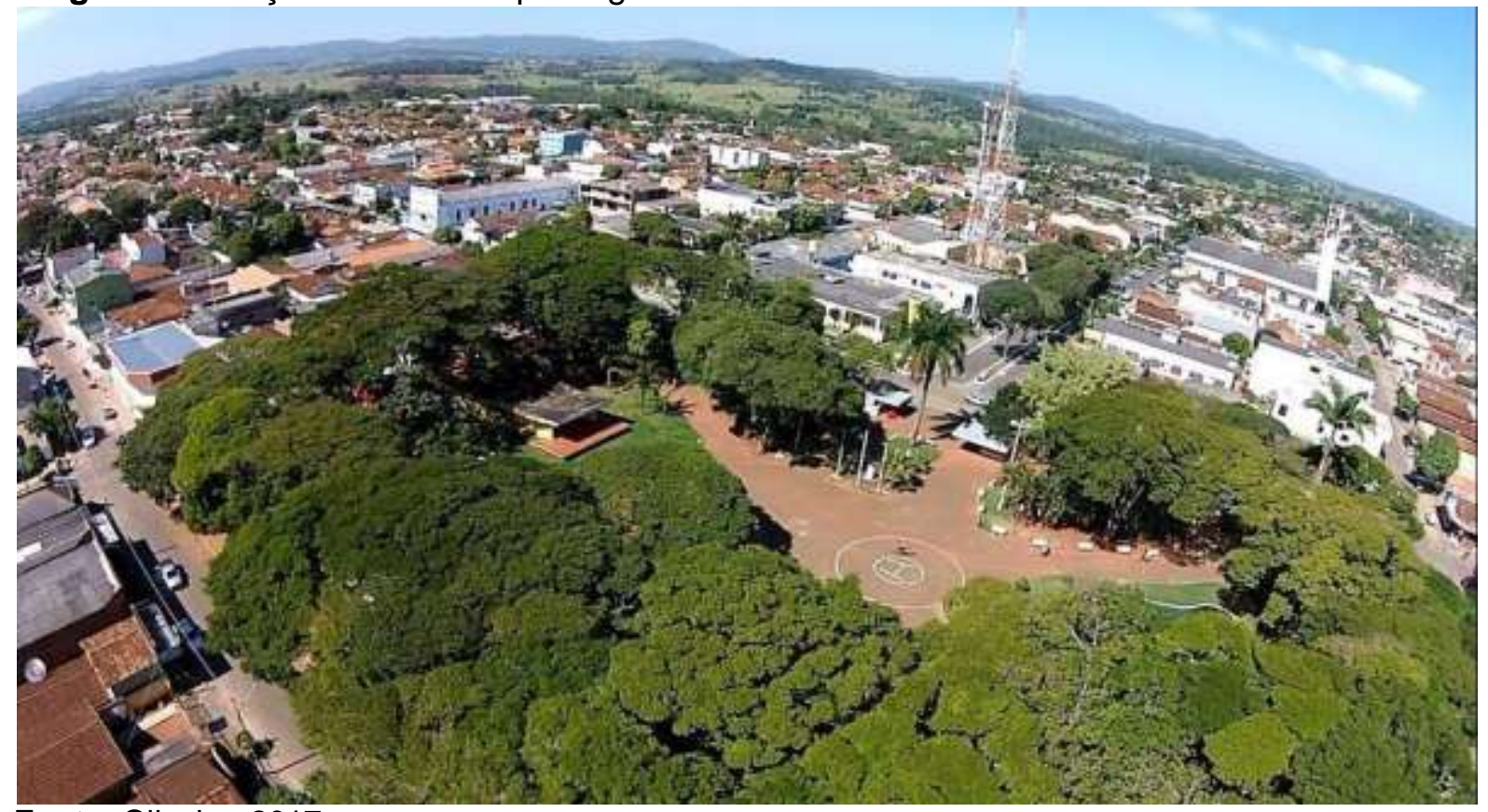

Fonte: Oliveira, 2017.

$\mathrm{Na}$ paisagem percebemos também alguns imóveis um pouco elevados (mas que não excedem dois andares), tratam-se de comércios, hotéis, instituições religiosas e moradias que revelam um possível embate socioespacial pela disputa de espaço no centro entre comerciantes, moradores e igreja. Este embate é promovido principalmente pela especulação imobiliária que se efetiva a partir de políticas públicas que visa investir melhor em infraestrutura principalmente na parte central da cidade. Por último, as torres de transmissão evidenciam a centralidade como um ponto estratégico e privilegiado, fundamental para transmitir sinal a toda cidade e que, de certa forma, também disputa espaços com comerciantes e moradores.

$\mathrm{Na}$ segunda imagem (figura 2) temos o cruzamento da Rua $48 \mathrm{com}$ a Rua Professor José Nunes de Lima. Este cruzamento é constituído por bares, restaurantes, sorveterias, instituições religiosas, comércio varejista e vendedores ambulantes, dentre outros. Trata-se de uma rede plural de atividades desenvolvidas no dia-a-dia. A figura apresenta as faixas e instrumentos de trânsito que evidenciam o cumprimento do poder público no sentido de evitar acidentes de tráfego. O conjunto de estabelecimentos de consumo lado a lado se assemelha a uma praça de alimentação de um shopping, o que chama a atenção para quem deseja alimentar-se de uma comida preferida ou desfrutar do lazer que o ambiente oferece. Tudo isso forma um conjunto de cores, formas e volumes que se evidencia na imagem e constitui a paisagem do centro, as estratégias de marketing introduzindo fachadas coloridas, painéis de LED (Light Emitting Diode), dentre outros que dão caraterísticas individuais ao 
local. Com isso podemos trazer como hipótese os tipos e preferências das pessoas frequentadoras destes ambientes, como turistas e alguns boêmios no período noturno, além dos consumidores ativos.

Figura 2 - Centro de Itapuranga

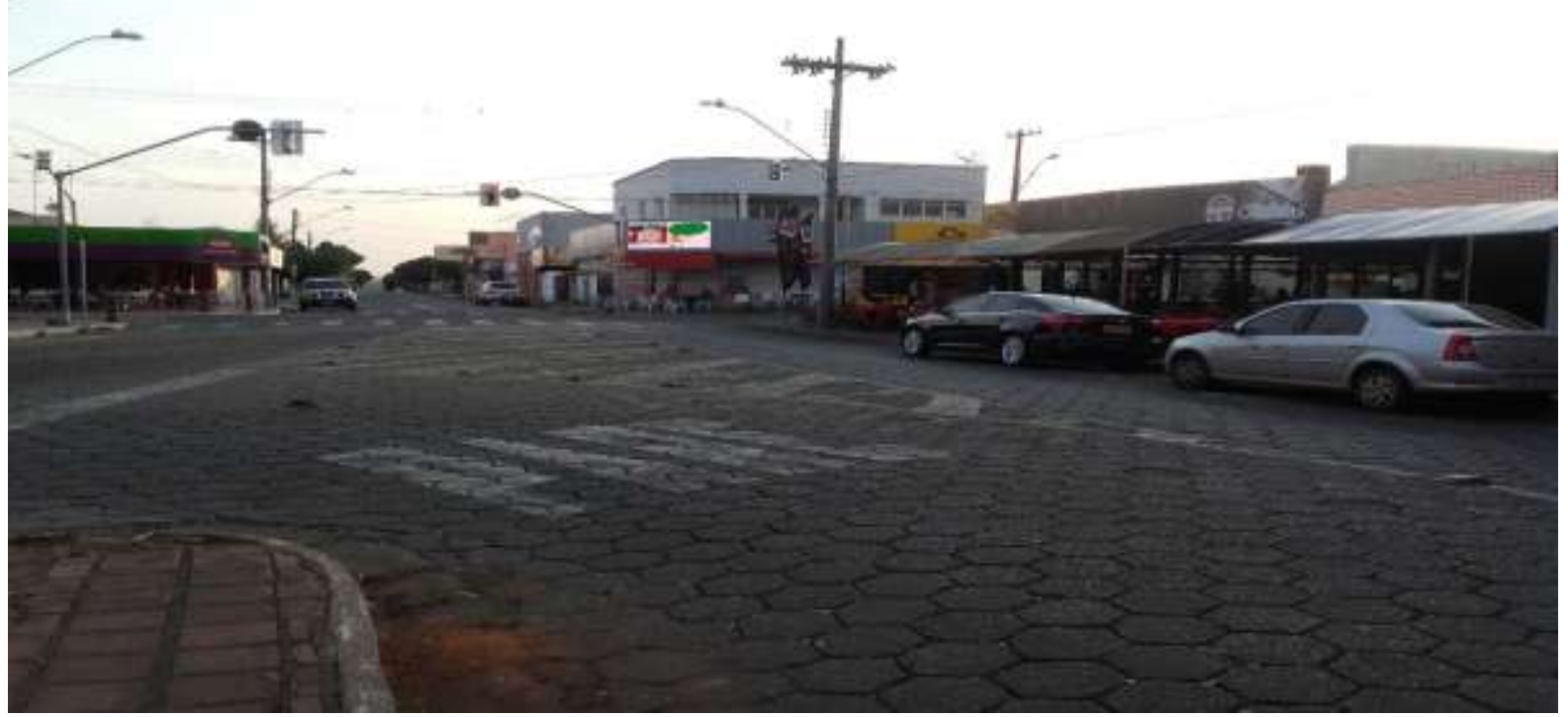

Fonte: Marins, 2017.

A terceira figura (figura 3) apresenta a via que tem o maior número de estabelecimentos comercias da cidade de Itapuranga, trata-se da Rua 45 que corta vários bairros, seu maior trajeto está no centro. A imagem mostra vários pontos comerciais e, além destes comércios, essa rua é onde se localizam algumas das principais instituições financeiras (bancos públicos e privados). O grande fluxo de automóveis legitima o número elevado de consumo e da mobilidade urbana, os vários estabelecimentos, também, nos levam a pensar em uma hipótese sobre o número elevado de empregos que são oferecidos nesta localidade, visto que um grande consumo exige uma significativa demanda de funcionários para o bom atendimento ao cliente. Mais uma vez destacamos a presença das cores além da arquitetura moderna que se mistura ao modelo arcaico das vias urbanas, visto como uma estratégia para chamar a atenção do consumidor. O número reduzido de árvores nas calçadas ajuda a não atrapalhar a vista das fachadas que foram produzidas estrategicamente no sentido de convidar os compradores a adentrarem ao estabelecimento.

As imagens revelam várias características intrínsecas existentes na área central da cidade de Itapuranga. Como qualquer outro meio urbano, independente da extensão, Itapuranga tem um centro formado por ruas, avenidas, casas, comércio, indústria e áreas de lazer, dentre outros. O centro tem uma dinâmica própria, quer se trate das relações sociais que ali se desenrolam no dia-a-dia, determinado por fatores que ao longo do tempo vão se (re)configurando e formando espaços de lazer, de compras e de negócios. 
Figura 3 - Rua 45, Centro

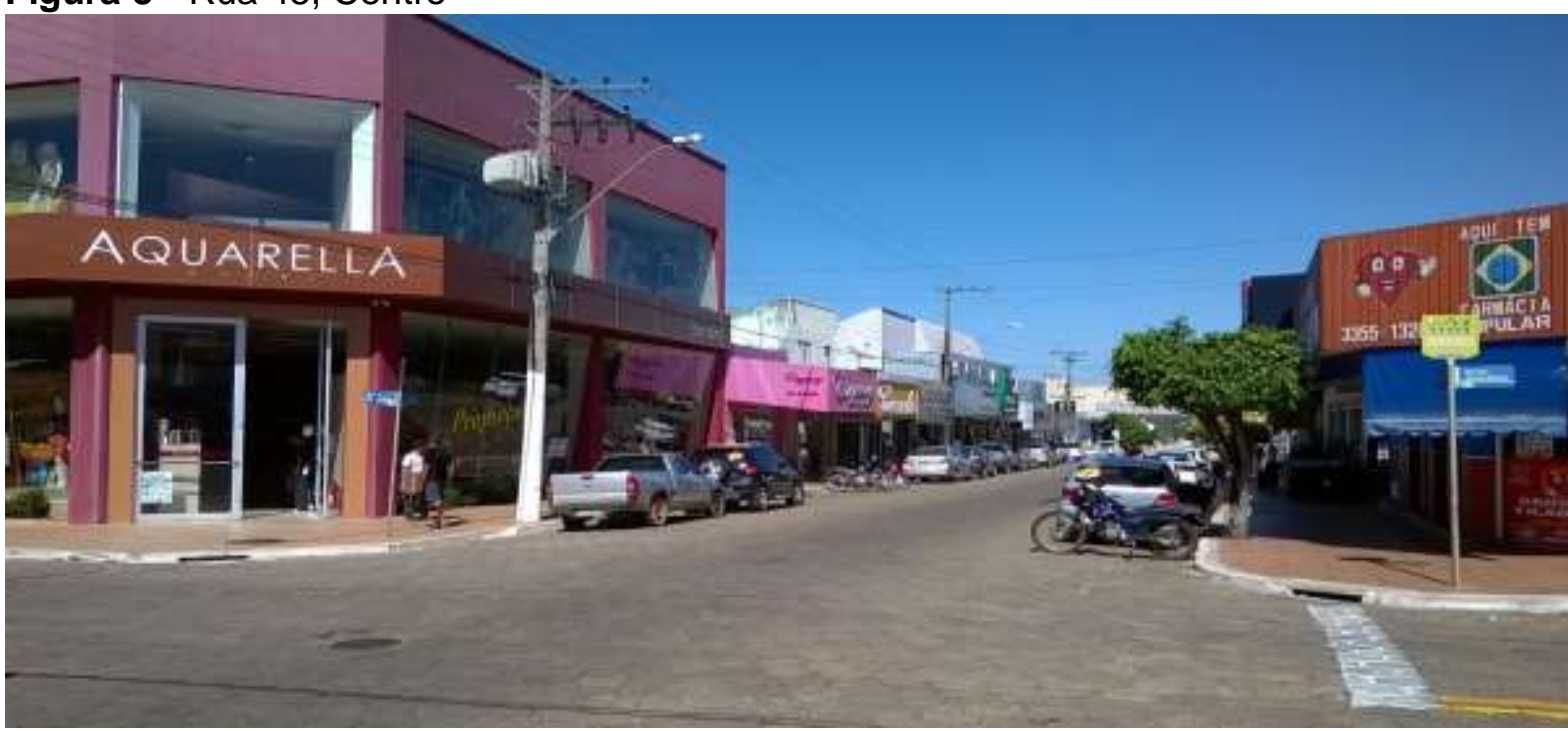

Fonte - Marins, 2017.

Podemos perceber, nas paisagens que foram apresentadas da área central, a configuração do tecido urbano, o conjunto de cores, formas, volumes, fluxo, sinais de trânsito, fachadas dos comércios, torres de transmissão, avenida saindo da praça central, coreto no interior da praça, outdoors digitais, enfim as várias características de uma centralidade complexa e rica em detalhes.

Confrontando com o que foi teoricamente discutido nos tópicos anteriores, a partir de uma visão sistemática, partindo do princípio do método empírico e tendo como suporte os estudos da semiótica, evidenciamos várias características de cunho social, cultural, econômico e político, que parte de um olhar crítico e reflexivo sobre a paisagem alvo de análise. Tais características a princípio surgem como hipóteses, mas que são sempre passíveis de análises partindo de um estudo histórico confrontado com a realidade, pois os símbolos que caracterizam uma paisagem vêm a caracterizar a comunidade local, sendo ela que a produz.

[...] podemos destacar o caráter simbólico da paisagem que, sendo portadora de significados, expressa valores e crenças. Como também, o caráter político que desvela 0 embate social, o confronto de poderes econômicos. A paisagem carrega em si marcas da história, do tempo atual e de tempos passados (MARIA, 2010, p. 52).

A partir das contribuições elencadas pela autora destacamos a primeiro momento 0 caráter histórico e político que trata de determinações das formas de organização. Quando nos deparamos com uma praça extensa que ocupa uma quadra localizada no centro urbano e que traz um nome de um ex-presidente, na verdade estamos nos deparando com um símbolo de "poder", mesmo após a morte a figura política ainda continua a ser relembrada a 
todo o momento, não apenas a figura de um cidadão político, mas para lembrar-se de um modelo de regime político que comandou o país durante um período da história. O mesmo se dá ao colocar um nome de um desbravador da bandeira paulista em avenidas, como foi destacado na imagem anteriormente (Avenida Anhanguera), onde se tem uma avenida que liga a Praça Castelo Branco até a Igreja Católica Matriz, localizada no Bairro São Sebastião do Xixá.

Num segundo momento, aproveitando ainda as escritas de Maria, ela traz o embate social através de confrontos de poderes econômicos, e tais questões se legitimam a partir do momento que presenciamos nas paisagens acima construções verticais, no qual se evidencia um possível embate causado pela especulação imobiliária, visto que o centro recebe uma atenção maior por parte do poder público quando comparado aos bairros periféricos habitados por pessoas de baixa renda. Logo, temos uma área central em que comércios, indústrias, instituições públicas, privadas e religiosas, além de moradores, disputam espaços que, a cada dia que passa fica mais escasso, e aí surge a necessidade de "verticalizar" as construções.

Portanto, concluindo a ideia da autora, a paisagem carrega em si marcas da história e de tempos atuais, ao analisa-la de forma sistemática identificamos uma série de características que "conta" um pouco da história de uma sociedade que antecede a estes grupos sociais que nos dias atuais produz também sua história, os simbolismos encontrados na paisagem dizem muito sobre essas sociedades. Cosgrove (2012, p. 236) escreve que "[...] a recuperação do significado em nossas paisagens comuns nos diz muito sobre nós mesmos [...]". Isso nos mostra como as caraterísticas de uma comunidade que está submetida às mesmas leis ou preceitos se fixam nos ambientes onde ela convive.

\section{PAISAGEM URBANA: FATOS ANALISADOS NO SUBÚRBIO DE ITAPURANGA}

A partir deste ponto, apresentaremos algumas paisagens da periferia de Itapuranga, local habitado por uma camada social de baixa renda. Dinâmica e complexa, a região periférica desta cidade tem suas próprias características, são paisagens carregadas de significados que revelam as realidades vivenciadas por uma comunidade que, às vezes, se difere e/ou se assemelha com aquelas vividas pela comunidade da área central. São re(produções) do espaço urbano que, dentre outros, determinam diversos problemas sociais.

A paisagem da figura 4 trata-se de uma imagem panorâmica do Conjunto Fraternidade e da Vila Mutirão, ambos localizados na periferia da cidade de Itapuranga. A figura revela vários detalhes que dão uma característica própria a estes bairros. Trata-se de alguns elementos importantes e de grande significância que caracterizam a paisagem: as ruas 
estreitas revelam um mau planejamento que, de forma inadequada, projetou a malha viária destes bairros no período de construção, outro detalhe importante é predominância de residências em detrimento dos comércios, no qual se revela os baixos investimentos no ramo do setor secundário (comércio).

Figura 4 - Periferia de Itapuranga (Conjunto Fraternidade e Vila Mutirão)

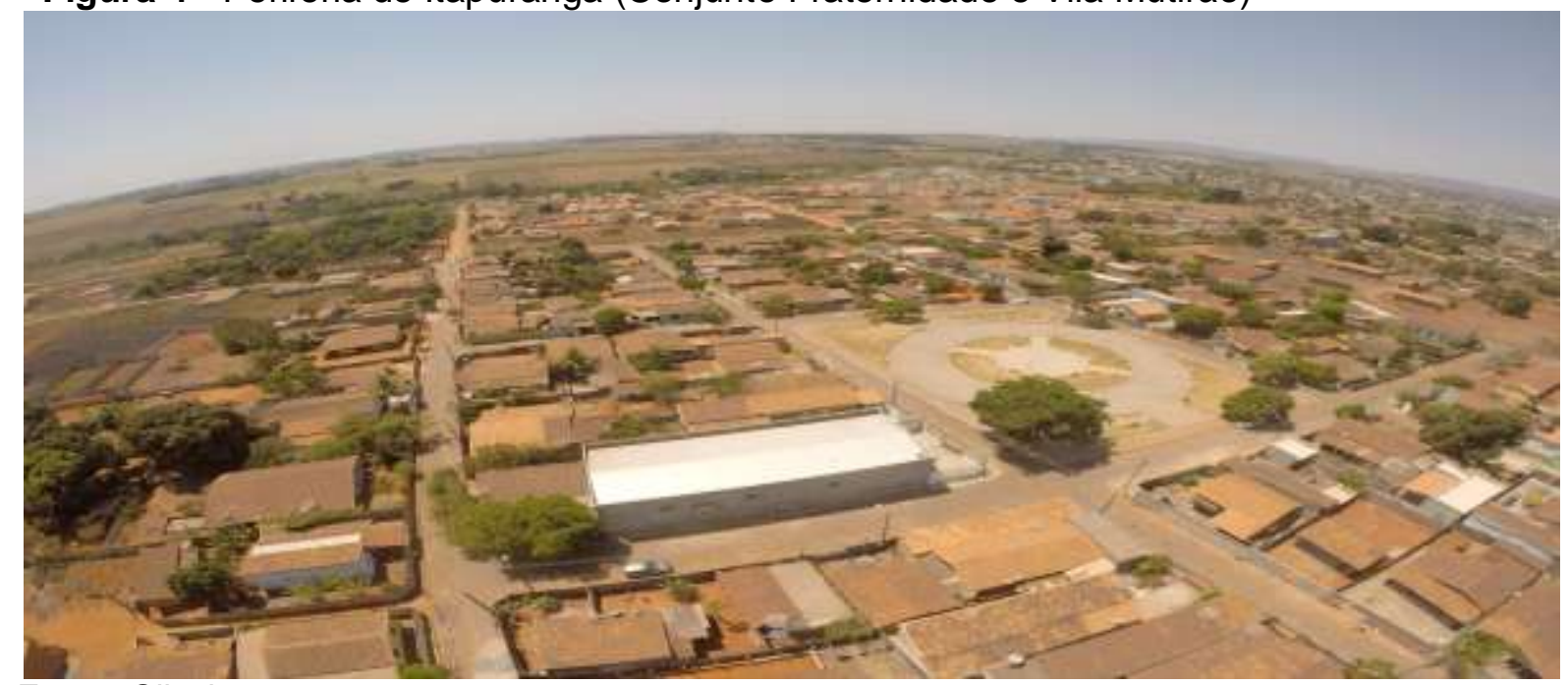

Fonte: Oliveira, 2017.

A praça de pequeno porte, pouca arborizada e sem ornamentações, foi fundada recentemente (2016), e sinaliza o comprometimento limitado por parte poder público quanto à promoção do lazer para a população local, pois se trata da única praça desta região. Neste sentido, poderíamos indagar o real motivo desta praça não possuir um coreto para os dias festivos como foi visto na praça central. Outro detalhe que chama a atenção é o limite dos bairros com o meio rural, o que legitima uma realidade de segregação socioespacial, visto que os bairros estão às margens da área urbana ou nas bordas da cidade. $O$ baixo fluxo de pessoas e automóveis revela a ausência de um polo comercial nesta região e, consequentemente, a baixa relevância no sentido econômico.

A paisagem da figura 5 exibe a entrada da Vila Mutirão (GO 230) que dá acesso ao Conjunto Fraternidade. A imagem nos aponta o abandono de um imóvel e, ao lado, resíduos espalhados pela calçada, fora de onde deveriam estar (dentro do container). Do outro lado temos a presença do pequeno comércio que é característico dos bairros de periferia, outro aspecto são as fachadas menos chamativas que aquelas localizadas na área central. Mais uma vez destacamos a análise das cores que compõe a imagem: quais são as cores predominantes nesta imagem em relação a do centro? Existe uma relação entre estas cores com a realidade social vivida pelos moradores? A discussão teórica que tivemos nos primeiros tópicos nos mostrou que não só as cores, mas um conjunto que abrange também formas e volumes trazem pequenos detalhes que podem trazer grandes significados. 
Figura 5 - Entrada da Vila Mutirão

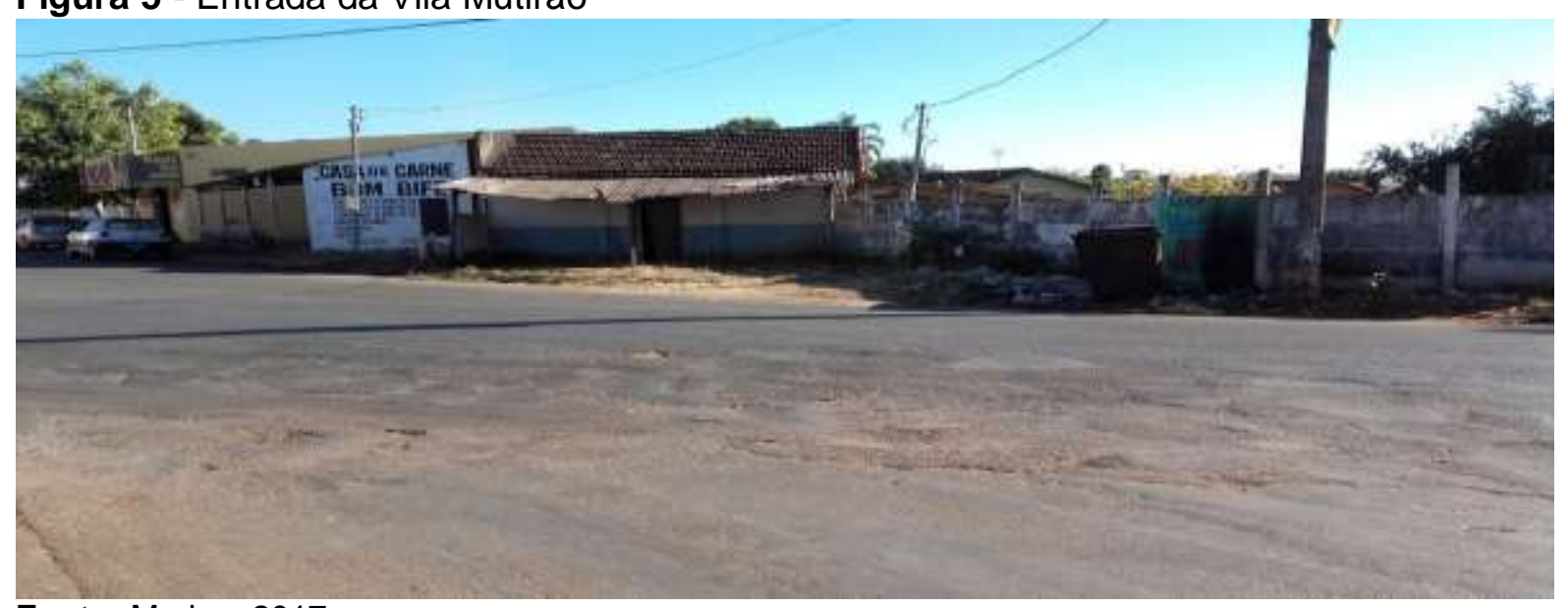

Fonte: Marins, 2017.

Por fim, a paisagem apresentada na figura 6 também expõe a realidade de abandono por parte do poder público, mostra um espaço sem uma função social definida. Esta fotografia foi registrada na esquina da Rua $03 \mathrm{com}$ a Rua C na vila Mutirão. Local que deveria funcionar como uma área de lazer ou algum outro equipamento público de consumo coletivo para a comunidade local se tornou um espaço ocioso ou sem algum tipo de aproveitamento, e a figura se destaca pelo sentimento de ausência.

Figura 6 - Vila Mutirão

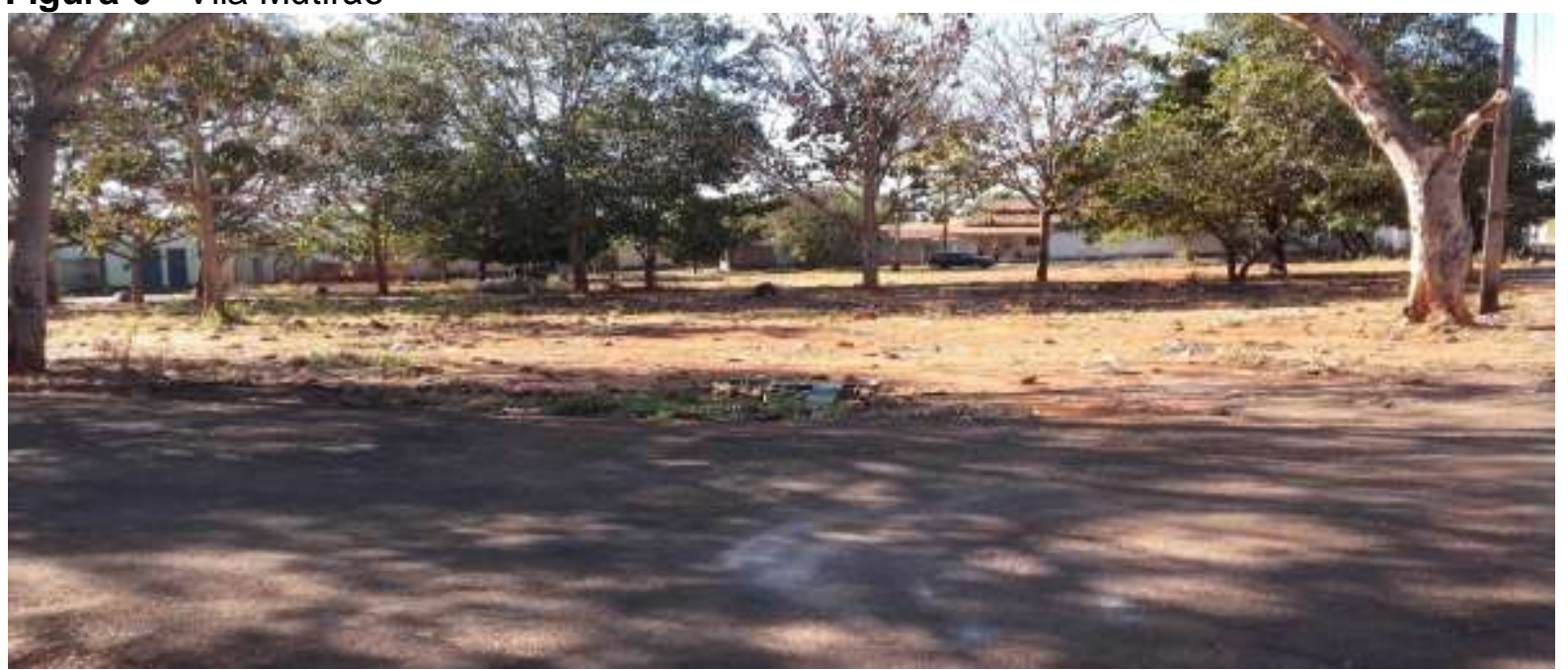

Fonte: Marins, 2017.

As imagens apresentadas das regiões da "periferia pobre" da cidade de Itapuranga revelam o lado obscuro do espaço urbano, trata-se na verdade de um espaço suburbano que nos mostra o contraste com as paisagens que vimos na parte central da cidade. Conforme discutido, a análise da paisagem a que este trabalho se propõe parte de uma análise crítica. Tal análise nos remete a realçar aquilo que há de diferente numa paisagem 
Elementos Teóricos e Sociais da Paisagem em Áreas Urbanas: um estudo semiótico no caso de...

em relação à outra, para que possamos identificar quais são as dessemelhanças que existem de um grupo social para outro e que possam ser identificadas ao decifrarmos o cenário social.

As paisagens dos bairros periféricos que foram vistas por meio das fotografias nos mostraram um ambiente que se opõe àquele que vimos no centro. Trata-se de um ambiente "fosco" que se apresenta com ruas estreitas e mal arborizadas, lugares abandonados pelo poder público e pela comunidade local, comércios pequenos e sem áreas de lazer. A segregação socioespacial é vista a partir do momento em que se percebe que o meio rural é limítrofe a estes bairros. Tais características na maioria das vezes passam despercebidas principalmente pela população que nasce, cresce e por ali reside. É uma forma de absorver o ambiente, pois o homem é um ser natural, logo é um elemento que faz parte e está presente nas diversas paisagens. Da mesma forma, para quem "assiste" de fora o dia-a-dia das pessoas marginalizadas, muitas das vezes ficam insensíveis com aquelas situações ditas como "normais" pela camada conservadora da população.

Marcelo Lopes de Souza (2013) em seu livro Os conceitos fundamentais da pesquisa sócio-espacial ao conceituar a categoria "paisagem", escreve sobre certa capacidade que a paisagem tem de não sensibilizar as pessoas a refletir sobre os problemas existentes na sociedade. Souza (2013, p. 57) escreve que "[...] outra potencialidade do conceito de paisagem para a pesquisa sócio-espacial reside em examinar como a paisagem condiciona a nossa (in)sensibilidade e o modo como somos socializados [...]". O que se tem na verdade é uma interferência da paisagem para com o modo que somos e fomos socializados, pois nos habituamos a deparar com ambientes que fogem dos padrões de bem-estar, do correto, do limpo, do organizado, do verde etc. Crescemos acreditando que tudo isso é normal, mesmo que tais características nos dizem que não está nada bem, pois, como sabemos, a paisagem nos diz muito sobre a comunidade que ali reside, vale repetir que são formas alternativas de ler o que está em nossa volta, trata-se de nos comunicarmos com o ambiente.

Portanto o que vemos nas paisagens da região periférica da cidade da camada menos favorecida é reflexo daquilo que se desenrola no dia-a-dia das pessoas que convivem nestes locais. Trata-se de uma resposta do que teoricamente discutimos ao conceituarmos paisagem, semiótica, linguística e espaço urbano. Na paisagem encontramos elementos que se tornam códigos que são decodificados a partir do que aprendemos sobre a semiótica. A ausência e o silêncio conforme destacado por Santaella (1983), também é um tipo de linguagem, como vimos nas paisagens dos bairros periféricos tais características estão presentes, porém de forma acusadora, mostrando certa carência que aquela população está sujeita. 
Portanto, cabe aqui uma análise de todos os elementos destacados nas paisagens da área central e dos bairros periféricos, é válido repetir que se trata dos volumes, cores, formas etc. Tais características estão presentes em ambos os bairros, todos são passíveis de análise de leitura sistematizada, tendo como suporte as teorias que aqui foram elencadas. De forma geral é necessário enfatizarmos a abrangente pluralidade linguística na qual estamos envolvidos, principalmente no que diz respeito a compreender as realidades das diversas comunidades que vivem nos diversos ambientes do espaço urbano.

É tal distração que a aparente dominância da língua provoca em nós que, na maior parte das vezes, não chegamos a tomar consciência de que o nosso estar-no-mundo, como indivíduos sociais que somos, é mediado por uma rede intrincada e plural de linguagem, isto é, que nos comunicamos também através da leitura e/ou produção de formas, volumes, massas, interações de forças, movimentos; que somos também leitores e/ou produtores de dimensões e direções de linhas, traços, cores (SANTAELLA, 1983, p. 11).

Constatamos que somos produtores do espaço que está em nossa volta e, nesse sentido, ao estudarmos o espaço urbano, percebemos que ele é dinâmico, trata-se de um espaço onde a sociedade mantém suas diversas relações de interesse. Sabemos que há interesses que diferem um do outro, é por isso que o espaço urbano é um campo de disputas, palco de diversos conflitos entre pessoas ou entre grupos de pessoas que competem algo que the traga vantagens, além disso, é nele onde há maior acúmulo de capital. Trata-se de um ambiente carregado de divergências, disputas, símbolos e poder, habitado por pessoas que muitas vezes pensam de formas distintas, e que, muitas vezes, agem sob o princípio do interesse próprio.

[...] o espaço urbano capitalista - fragmentado, articulado, reflexo, condicionante social, cheio de símbolos e campos de lutas - é um produto social, resultado de ações acumuladas através do tempo, e engendradas por agentes que produzem e consomem espaço. São agentes sociais concretos, e não um mercado invisível ou processos aleatórios atuando sobre um estado abstrato. A ação destes agentes é complexa, derivando da dinâmica de acumulação de capital, das necessidades mutáveis de reprodução das relações de produção, e dos conflitos de classe que dela emergem (CORRÊA, 1989, p. 12).

Temos, portanto, algumas características vistas com um olhar crítico acerca do meio urbano, formado por agentes sociais que consomem e alteram a paisagem a todo instante, sucessores daqueles que fizeram o mesmo no passado e deram início a projetos e ações que foram se acumulando ao longo do tempo. São importantes análises do que se passa em nossa volta. A cidade é um produto da sociedade, fruto de processos complexos que derivam, sobretudo, do sistema capitalista de produção. Isso não significa que é algo 
invisível, porém muitas vezes passa despercebido aos nossos sentidos. Para Corrêa (1989), tais relações derivam, dentre outras, das lutas de classes. Isso significa que há diferenças sociais e econômicas entre grupos de pessoas no meio urbano, gerando conflitos e criando relações de poder entre as pessoas ou grupo de pessoas e reforçando a ideia de uma complexidade característica da cidade.

A paisagem urbana é fruto de um processo social que se modifica de forma instantânea por meio das relações que se desenrolam no dia-a-dia, mas que, ao mesmo tempo, aparenta ser estática, pois só percebemos determinadas "mudanças visuais" num maior espaço de tempo. Maria (2010, p. 20) defende que "[...] a paisagem, é aqui compreendida como fruto da relação entre as sociedades, suas culturas e a natureza". A cultura de um povo, ou de uma comunidade, está representada na paisagem, há o destaque do domínio do homem sobre a natureza, no sentido de modificá-la, que também é representada neste cenário. Para Souza (2013, p. 48-49), "O fato de ser uma forma, uma aparência, significa que é saudável "desconfiar" da paisagem. É conveniente sempre buscar interpretá-la ou decodificá-la à luz das relações entre forma e conteúdo, aparência e essência". Com essas palavras, é válido refletir diante da forma que nos posicionamos frente aos diversos elementos formadores da paisagem urbana, é preciso sempre ultrapassar o exterior, analisar o interior, para que o todo seja compreendido.

\section{CONSIDERAÇÕES FINAIS}

Ao explorarmos o campo da Geografia percebemos a gama de conteúdo que esta ciência traz em seu bojo, o vasto campo dos estudos geográficos nos traz infinitas buscas e conclusões dos mais diversos conteúdos que fazem parte da existência humana. O nosso meio está carregado de informações, é sempre virtude de um pesquisador saber lidar com as várias informações que circulam pelos ambientes.

Ao analisarmos a paisagem nos deparamos com o desafio de uma leitura sistematizada baseada na semiótica tendo como finalidade compreender as realidades sociais registradas no ambiente social. Seja uma comunidade localizada na periferia, uma área central ou um condomínio fechado afastado das conturbações, todos estes locais estão rodeados de marcas e registros e cabe ao pesquisador, independente de campo específico, ter a percepção destes sinais deixados pela sociedade e, principalmente, não deixar de se posicionar de forma crítica às essas diferenças.

A intrínseca relação cidade-paisagem-semiótica se legitima a partir do momento em que absorvemos a ideia da semiologia como ciência de todas as linguagens e um caminho para entendermos as relações sociais urbanas a partir dessa rede plural de linguagem, ou seja, a leituras das formas, massas, volumes e cores. Além disso, é necessário que 
tenhamos consciência de que, além de leitores, somos produtores destes meios de linguagem, pois fazemos parte dessa sociedade, e, portanto, deixamos marcas e símbolos nos ambientes que ocupamos.

Portanto, deixamos aqui reflexões para pensarmos sobre o cenário urbano, na busca de uma leitura crítica dos ambientes que, muitas vezes, são ignorados, principalmente pelas pessoas que não fazem parte daquela realidade ou não vivenciam as diferenças, pois um ambiente em termos de aparência se diferencia de outros em vários aspectos. Nosso meio é carregado de informações, por isso é preciso explorá-las a fim de obter respostas acerca dos fatores que estão interpostos no meio social. Em todo o cenário existem bastidores e cabe ao leitor crítico de tais realidades buscar entender os processos que acontecem "por debaixo dos panos", repensando sempre tudo aquilo que está sujeito a percepção pelos nossos sentidos.

\section{REFERÊNCIAS}

BACELAR, J. Linguagem da visão. Biblioteca On-line de Ciências da Comunicação, Covilhã, PT, 1998. Disponível em: <http://www. bocc. ubi. pt/pag/bacelar_linguagem>. Acesso em: 29 mar. 2017.

CORRÊA, R. L. O espaço urbano. São Paulo: Ática, 1989.

COSGROVE, D. A geografia está em toda parte: cultura e simbolismo nas paisagens humanas. In: CORREA, R. L.; ROSENDAHL, Z. (Org.). Geografia cultural: uma antologia. Rio de Janeiro: UERJ, 2012. p. $219-236$.

COSGROVE, D. Mundos de significados: geografia cultural e imaginação. In: CORREA, R. L.; ROSENDAHL, Z. (Org.). Geografia cultural: um século. Rio de Janeiro: UERJ, 2000. p. $33-60$.

COSGROVE, D. Social formation and symbolic landscape. Londres: Wisconsin Press, 1998. Disponível em: <http://books.google.com.br/books?hl=pt-BR\&lr=\&id=NrD2nJ52aYC\&oi=fnd\&pg=PR9\&dq=Cosgrove\&ots=CpOuelbTV8\&sig = Fid XU

R8P8oER9YLtl8HzhlzWGc\#v=onepage\&q=\&f=tree>. Acesso em: 20 maio 2017.

IBGE. Cidades. Itapuranga. Disponível em: <https://cidades.ibge.gov.br/brasil/go/itapuranga/panorama>. Acesso em: 23 mar. 2017.

MARIA, Y. L. Paisagem: cultura-natureza em perspectiva - uma abordagem trajetiva do conceito de paisagem. 2016. Tese (Doutorado Geografia Física) - Faculdade de Filosofia, Letras e Ciências Humanas, Universidade de São Paulo, São Paulo.

MARIA, Y. L. Paisagem: entre o sensível e o factual: uma abordagem a partir da geografia cultural. 2010. Dissertação. (Mestrado em Geografia Humana) - Faculdade de Filosofia, Letras e Ciências Humanas, Universidade de São Paulo, São Paulo.

NAME, L. O conceito de paisagem na geografia e sua relação com o conceito de cultura. GeoTextos, Rio de Janeiro, v. 6, n. 2, p. 163 - 186, dez. 2010. 
NUNES, C. A paisagem como teatro. In: YÁZIGI, E. Paisagem e turismo. São Paulo: Contexto, 2002. p. $215-223$.

ORLANDI, E. P. O que é lingüística. São Paulo: Brasiliense, 2003.

PINHEIRO NETO, J. E. Tessituras da paisagem cultural às margens do rio Capibaribe e no Recife sob a luz da poética de João Cabral de Melo Neto. 2017. Tese (Doutorado em Geografia Humana) - Faculdade de Filosofia, Letras e Ciências Humanas da Universidade de São Paulo, São Paulo.

SANTAELLA, L. O que é semiótica. São Paulo: Brasiliense, 1983.

SANTOS, J. L. O que é cultura. São Paulo: Brasiliense, 2003.

SANTOS, M. Metamorfose do espaço habitado: fundamentos teóricos e metodológicos da geografia. São Paulo: Hucitec, 1994.

SOUZA, M. L. de. Os conceitos fundamentais da pesquisa sócio-espacial. Rio de Janeiro: Bertrand Brasil, 2013. v. 1.

Recebido: maio de 2018. Aceito: setembro de 2018. 